\title{
Metabolomics applied in bioenergy
}

\author{
Patricia V Abdelnur ${ }^{1}$, Camila Caldana ${ }^{2,3^{*}}$ and Marina C M Martins ${ }^{3}$
}

\begin{abstract}
Metabolomics, which represents all the low molecular weight compounds present in a cell or organism in a particular physiological condition, has multiple applications, from phenotyping and diagnostic analysis to metabolic engineering and systems biology. In this review, we discuss the use of metabolomics for selecting microbial strains and engineering novel biochemical routes involved in plant biomass production and conversion. These aspects are essential for increasing the production of biofuels to meet the energy needs of the future. Additionally, we provide a broad overview of the analytic techniques and data analysis commonly used in metabolomics studies.
\end{abstract}

Keywords: Metabolomics; Mass spectrometry; Bioenergy

\section{Introduction}

The rising demand for energy, coupled with uncertain sources of fossil fuels and concerns over the effects of increasing carbon dioxide, has contributed to the search for alternative energy sources. In this sense, the translation of biomass derived from crop plants into biofuels has emerged as an attractive solution. Currently, sucrose from sugarcane and starch from corn are used as feedstock for ethanol fermentation. However, there is increasing interest in using the bulk of plant biomass in the form of cell walls $[1,2]$ or triacylglycerols [3] to meet the energy needs of the future. Some attempts to make the production of lignocellulosic biofuels possible include the development of strategies to harness structural sugars from plant cell walls by prospecting novel microbial enzymes and biomass-oriented plant breeding. However, to achieve this, it is necessary to understand the molecular mechanisms underlying plant biomass production [4] and microbial conversion pathways [5,6]. These processes rely on complex signaling networks closely linked to the metabolism. Therefore, understanding how plants and microorganisms grow in response to environmental stimuli and how they can adjust their metabolic ratios could also provide means to simplify the conversion of biomass into biofuels [7].

\footnotetext{
* Correspondence: camila.caldana@bioetanol.org.br

${ }^{2}$ Brazilian Bioethanol Science and Technology Laboratory/CNPEM, Rua Giuseppe Máximo Scolfaro 10000, Campinas, SP 13083-970, Brazil

${ }^{3}$ Max-Planck-partner group at the Brazilian Bioethanol Science and Technology Laboratory/CNPEM, Rua Giuseppe Máximo Scolfaro 10000, Campinas, SP 13083-970, Brazil

Full list of author information is available at the end of the article
}

Recent advances in high-throughput technologies and analytic methods, such as transcriptomics and metabolomics, have enabled measurements of phenotypic variations at the molecular level. The metabolome, which represents the chemical composition of all small molecules in a cell or organism under certain conditions, allows for a global view of cellular and physiological functions. In comparison to other technologies, metabolomics is cheaper per sample than transcriptomics and is not reliant on the availability of genome sequences $[8,9]$. Therefore, it is considered a powerful tool for the unbiased characterization of genotypes and phenotypes with application in multiple areas, such as evaluation of genetically modified organisms [10-12], functional genomics [13-17], responses to environmental factors [18-23], metabolic engineering [24,25], and quantitative genetics [26-30]. Furthermore, metabolomics, together with multivariate and correlation analyses, is an excellent tool for the study of systems biology, being widely recognized as the cornerstone of this emerging area [22,31-34]. In this review, we focus on how metabolomics approaches have been used to identify novel metabolic routes for microbial biomass conversion and also highlight biochemical pathways important for plant biomass production. Furthermore, we provide a brief overview of advancements in analytic techniques and data analysis commonly used in metabolomics studies.

\section{Review \\ Overview of metabolomics approaches \\ Despite significant advancement in analytic tools, complete coverage of the metabolome will always be constrained by}

\section{Springer}


polarity, stability, dynamic range, and biological properties of metabolites [35]. Currently, there is no single technology available for the detection of all metabolites present in an organism [36-38]. Therefore, the optimal choice for an analytic technology will largely depend on the goal of each study and is usually a compromise of selectivity and speed [36]. Because of this, numerous protocols for metabolite analysis have been developed to cover a broad range of compound classes, which are frequently characterized by the following workflow, as summarized in Figure 1: (i) material of choice, (ii) sample preparation and extraction, (iii) analytical methods, (iv) data processing and (v) data analysis and interpretation.

\section{Sample preparation and extraction}

The choice and optimization of sample preparation procedures are crucial steps for metabolomics analysis, as the efficiency and balance of compounds moving from the biological sample into the extract will determine the quality of the extract and thus must represent the original material $[39,40]$. At this stage, one must carefully select the sample material (e.g., cells, tissues, organism),

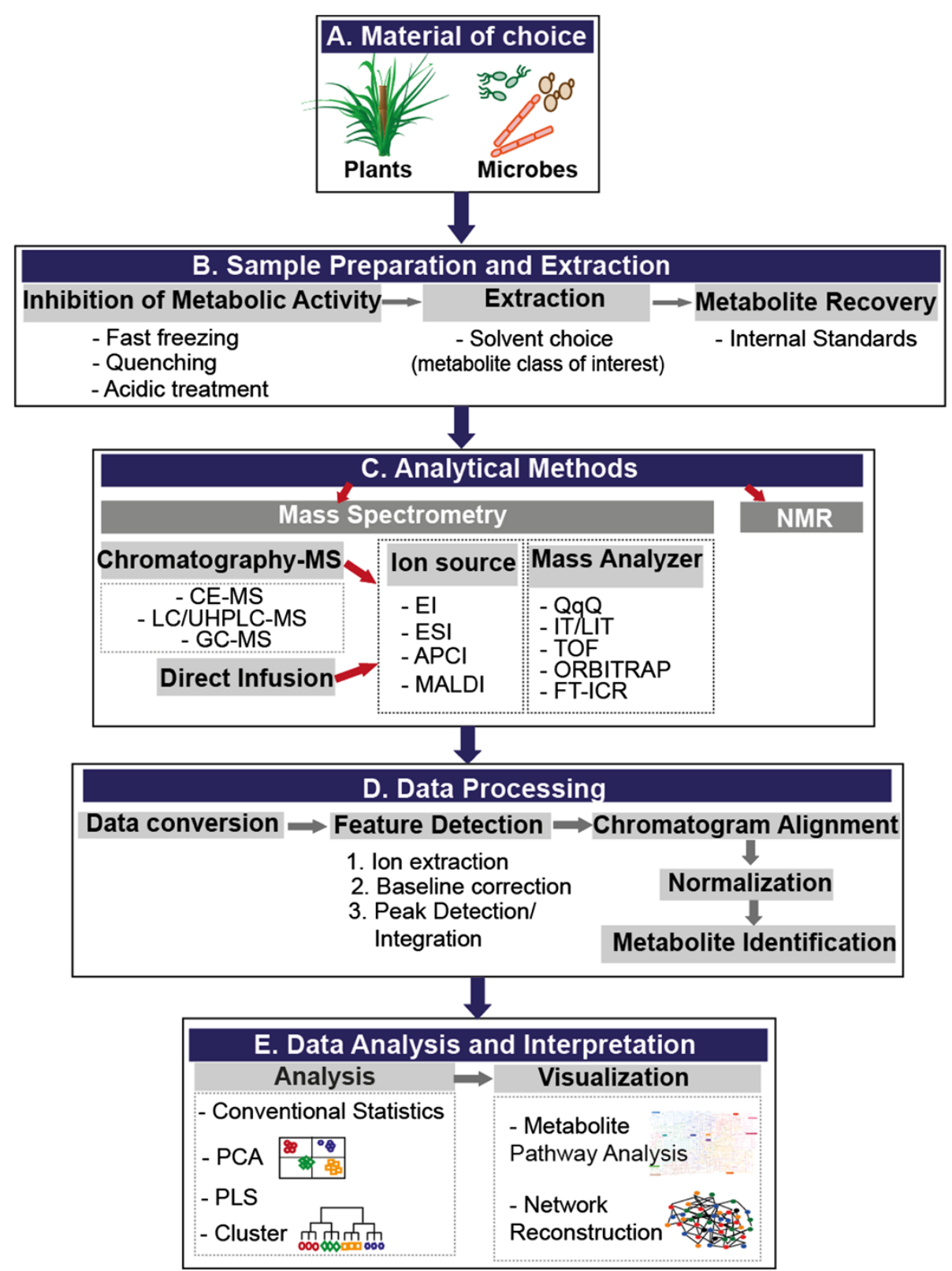

Figure 1 Material of choice (A), sample preparation and extraction (B), analytical methods (C), data processing (D), and data analysis and interpretation (E). 
conditions for cultivation, and the strategy for harvesting, ensuring a minimal number of replicates (Figure 1A).

Immediately after harvesting, inactivation of the metabolic processes is critical to avoid the loss of metabolites with high turnover (Figure 1B). The most common method employed for this end is rapid freezing by liquid nitrogen, although quenching or acidic treatment are also appropriate alternatives [41-47].

Different extraction protocols tailor to different compound classes based on several solvents (e.g., methanol/ water/chloroform mixture used for simultaneous extraction of both hydrophilic and hydrophobic compounds or solid phase extraction used for volatile metabolites [40]), limiting coverage of the metabolome (Figure 1B). Due to the fact that metabolites differ greatly in their concentrations, structures, and chemical behaviors, extraction buffer composition, temperature, and period of extraction must all be optimized. Additionally, as the extraction process introduces an element of bias (not all compounds will be extracted with the same efficiency), this will be reflected in the analytes detected and measured $[35,37,40]$. In order to assess metabolite recovery from the sample, internal standards are often spiked in the extraction buffer, functioning also as a correction factor for quantification [37] (Figure 1B). Finally, depending on the choice of the analytic technology, a derivatization step or re-suspension in a solvent compatible with the chromatographic separation might be necessary.

\section{Separation and detection: analytic techniques}

In recent years, many efforts have contributed to the achievement of a more comprehensive coverage of the metabolome, mainly using mass spectrometry (MS) and nuclear magnetic resonance (NMR) (Figure 1C). Although NMR has many advantages, such as high selectivity, nondestructive, relative stability of chemical shifts, and ease of quantification $[48,49]$, its low sensitivity places MS as the most frequently used technology in metabolomics studies. MS's main features are high sensitivity, high resolution, wide dynamic range, robustness, and feasibility in elucidating the molecular weight and structure of unknown compounds. A mass spectrometer consists of three primary components, namely ion source, mass analyzer, and detector, that provide mass-to-charge ratio information [36,49-51]. Nowadays, there is a wide range of MSbased technologies, which differ in operational principles and performance [36,51-58]. Great advancements have been achieved with the combination of different ionization sources (e.g., electrospray ionization (ESI), electron impact ionization (EI)) and mass analyzers with various resolving power (e.g., Fourier transform ion cyclotron resonance (FT-ICRMS), orbitrap, time of flight (TOF), and linear traps) [36,51,58]. Tables 1 and 2 provide an overview of the most common ionization techniques and mass spectrometer analyzers, respectively. Many reviews have focused on available analytic technologies, and more detailed information can be found in Lei et al. [36], Dass [51], Villas-Bôas et al. [59], and Saito et al. [60].

There are two MS strategies currently incorporated into metabolomics: direct-infusion MS and chromatography coupled to MS (Figure 1C, Table 3). The first approach uses soft ionization for mass peak assignment, promoting reduced or no fragmentation of fragile thermolabile molecules and results in a fast high-throughput screening tool [59] suitable for various studies such as microbial diversity [62], lipidomics analysis in plants and microorganisms $[63,64]$, plant-microbe interactions [65], among others. On the other hand, in MS coupled to chromatographic separation, the complexity of the biological sample and mass spectra is reduced, improving the separation of isomers, compound quantification and, consequently, accuracy and sensitivity [36,37]. In this context, the most widely used separation techniques are gas chromatography (GC), liquid chromatography (LC), and capillary electrophoresis (CE). As for other analytic tools, the choice of methodology relies on the compound class of interest. For instance, GC-MS is extensively used for the analysis of semi-polar primary metabolites due to its heat stability, which is applicable for modifications through derivatization reactions that make them volatile [41], whereas LC-MS has been particularly employed for lipid or plant secondary metabolites [66-68]. In recent years, advances in high performance (e.g., fast GC and ultra-high performance liquid chromatography UHPLC) or multidimensional columns (e.g., GC $\times$ GC and $\mathrm{LC} \times \mathrm{LC}$ ) have allowed for an increase in resolution,

Table 1 Most common ionization techniques used for metabolomics applications

\begin{tabular}{|c|c|c|}
\hline Ionization techniques & Options & Advantages \\
\hline Electron impact & & $\begin{array}{l}\text { Most popular for organic compounds with molecular mass <600 Da, } \\
\text { best-characterized ionization method }\end{array}$ \\
\hline Spray ionization & $\begin{array}{l}\text { Atmospheric pressure chemical } \\
\text { ionization (APCI) }\end{array}$ & $\begin{array}{l}\text { Applicable to relatively less polar and thermally stable compounds with an upper } \\
\text { mass range of } 1,500 \mathrm{Da} \text {, improved ionization efficiency and detection sensitivity }\end{array}$ \\
\hline & Electrospray ionization (ESI) & $\begin{array}{l}\text { Characterization of small and large biomolecules (charged, polar, or basic), } \\
\text { ultrahigh detection sensitivity, can control presence of fragmentation }\end{array}$ \\
\hline $\begin{array}{l}\text { Laser desorption } \\
\text { ionization }\end{array}$ & $\begin{array}{l}\text { Matrix-assisted laser desorption/ionization } \\
\text { (MALDI) }\end{array}$ & $\begin{array}{l}\text { Applicable to large biomolecules with masses }>200 \text { kDa, sensitivity of several } \\
\text { orders of magnitude }\end{array}$ \\
\hline
\end{tabular}


Table 2 Overview of the most frequently used mass spectrometer analyzers for metabolomics applications

\begin{tabular}{lccc}
\hline Mass analyzer & Mass accuracy $(\mathbf{p p m})$ & Resolving power $(\mathrm{FWHM})\left(\times 1 \mathbf{0}^{\mathbf{3}}\right)$ & Mass range $(\mathbf{m} / \mathbf{z})\left(\times 1 \mathbf{0}^{\mathbf{3}}\right)$ \\
\hline Triple quadrupole (QqQ) & $5-500$ & Up to 7.5 & 3 \\
lon trap (IT)/linear ion trap (LIT) & $50-500$ & Up to $\sim 10$ & 4 \\
Time of flight (TOF) & $1-2$ & $10-60$ & $5-40$ \\
Orbitrap & $1-5$ & $140-240$ & $4-6$ \\
Fourier transform ion cyclotron resonance (FT-ICR) & $<1$ & $750-1,000$ & $4-10$ \\
\hline
\end{tabular}

Adapted from [61].

providing faster analysis and better peak separation of complex biological mixtures [50].

\section{Data processing, analysis, and interpretation}

The ultimate goal of metabolomics experiments is to have a final matrix that can be subjected to a range of statistical tools in order to link the differences in biochemical levels to the phenotype [68]. However, as a high-throughput technology, metabolomics datasets are extremely large and require multiple tools for data information and management, raw analytical data processing, compound standardization and ontology, statistics, integration, visualization, mathematical modeling of metabolic networks, and interpretation (Figure 1D,E) [69]. Excellent reviews are available providing a detailed description of each step, and metabolomics databases can be found in Fukushima and Kusano [38], Kopka et al. [69], Redestig et al. [71], Boccard and Rudaz [72], Xia and Wishart [73], Fiehn et al. [74], and Redestig et al. [75].

The most challenging aspect of data analysis is raw data processing, which involves data conversion, baseline correction, spectrum deconvolution, peak detection and integration, chromatogram alignment, normalization, and compound identification and quantification (Figure 1D). There are a number of commercial and open source programs that automatically perform those steps and can be effectively used for each specific analytical platform (e.g., Target Search [76] or TagFinder [77] for GC-MS) or a combination of them (e.g., MetAlign [78] or XCMS [79] for GC-MS or LC-MS).

For comparison of biological groups (e.g., control and treated samples, mutant and wild type), a wealth of statistical and machine learning algorithms using unsupervised (e.g., hierarchical clustering and principal component analysis) or supervised (e.g., ANOVA, partial least squares) methods enable comprehensive identification of variables (metabolic features) in order to capture the dimension of variation among the entire dataset (Figure 1E) $[69,70,74,80,81]$. After this, data visualization tools allow for the simplification and incorporation of metabolic data into biochemical pathways, facilitating interpretation (Figure 1E). Several tools have been developed as highlighted in [38]; however, their utilization is still limited to annotated pathways.

\section{Metabolomics applications for bioenergy Microbial metabolomics}

The metabolism of several microorganisms is innately able to produce ethanol as well as other 'advanced biofuels' such as long-chain alcohols and isoprenoid- and fatty acid-based fuels [82]. Likewise, the myriad of ecological niches occupied by microbes provides the opportunity for prospection of novel biochemical pathways, allowing for better conversion of residual biomass. Finally, microorganisms have great biotechnological potential for the engineering and/or incorporation of complete exogenous metabolic pathways for the production of value-added chemicals. Despite the

Table 3 Comparison of direct infusion and hyphenated techniques in mass spectrometry

\begin{tabular}{|c|c|c|}
\hline MS strategy & Advantages & Disadvantages \\
\hline \multirow[t]{6}{*}{ Direct-infusion MS } & - Simple sample preparation & - Not recommended for complex matrix \\
\hline & - No pre-separation steps & - Ion suppression effect \\
\hline & - Fast analysis & - Complex mass spectra \\
\hline & - Low solvent consumption & \\
\hline & - High-throughput screening tool & \\
\hline & - Most used for qualitative analysis & \\
\hline \multirow[t]{3}{*}{$\begin{array}{l}\text { Chromatography } \\
\text { coupled to MS }\end{array}$} & $\begin{array}{l}\text { - Better accuracy and sensitivity for } \\
\text { the analysis of complex mixtures }\end{array}$ & $\begin{array}{l}\text { - Pre-separation steps depending on } \\
\text { chemical composition of samples }\end{array}$ \\
\hline & - Less ion suppression effect & - Longer time required for analysis \\
\hline & - Most used for quantitative analysis & - Wastes large amount of solvents \\
\hline
\end{tabular}


unlimited capability of microorganisms for biomass conversion and biofuel production, there is still a lack of information about the metabolic networks underlying these processes.

Yeast cells are constantly exposed to multiple stress conditions (e.g., high temperature and low $\mathrm{pH}$ ) during the industrial fermentative process, and consequently, there is growing interest in identifying novel strains with better performance. The metabolic differences of diploid $(\alpha / a)$ and haploid $(\alpha, a)$ yeasts in response to ethanol stress were recently assessed by GC-MS-TOF [83]. The results indicated that the haploid genotype was more susceptible to ethanol stress than the diploid due to its higher content of protective metabolites including polyols [83]. These findings indicate the power of metabolomics for the selection of genotypes or identification of candidate genes/paths for metabolic engineering.

Xylose is the second most abundant fermentable sugar in lignocellulosic feedstocks [84]; however, commercial yeast strains are unable to convert it into ethanol [85] (reviewed in [86]). For this reason, prospection of naturally xylose-fermenting yeasts species (e.g., Scheffersomyces stipitis or Pachisolen tannophilus), comparative genomics, and evolutionary analysis have been used as strategies to determine the limiting steps in pentose metabolism $[89,90]$. Although the identified functional enzymes were expressed in recombinant Saccharomyces cerevisiae industrial strains, their efficiency in fermenting xylose was shown to still be quite low $[87,88]$, suggesting the requirement of additional modifications. Overexpression of genes encoding enzymes of non-oxidative pentose phosphate pathway (PPP) [89], replacement of a small amount of enzymes of xylose metabolism [90], as well as isolation of xylose transporters [91,92] were pointed out as crucial factors for the adequate function of this pathway. However, a more holistic approach could also provide the metabolic reconstruction of most biologically relevant and predictive models to improve the fermentative ability of $S$. cerevisiae [93]. Recently, dynamic metabolomics studies of two recombinant strains of $S$. cerevisiae during anaerobic batch fermentation of a glucose/xylose mixture were conducted using LC-MS [22]. The results suggest that xylose can be primarily used as an energy source, as both strains maintained a high energy charge during the transition to xylose fermentation. However, it seems that xylose fermentation uncouples energy and carbon metabolism [22]. These findings were uncovered solely through metabolomics analysis.

Biomass pre-treatment using consolidated bioprocessing combines enzyme production, saccharification, and fermentation and leads to the production of toxic compounds (e.g., weak acids), which can inhibit yeast growth and, consequently, ethanol yield. Recently, the effect of acetic acid was analyzed by metabolomics during xylose fermentation in a recombinant strain of S. cerevisiae using GC-MS and
CE-MS [25,34]. The results revealed a significant accumulation of intermediates of PPP, indicating a slowdown of the metabolic flux [25]. Based on these findings, the authors generated a recombinant xylose-fermenting strain overexpressing the gene encoding a PPP-related enzyme, transaldolase, which conferred increased ethanol productivity in the presence of acetic and formic acids [25]. This study demonstrated the strength of metabolomics in developing rational strategies to improve tolerance to stresses through genetic engineering.

One promising area in bioenergy is the development of microbial cell factories as a platform for producing advanced biofuels, such as 1-butanol or biodiesel [6]. In most of these cases, however, genetic engineering of entire exogenous pathways to yield those compounds does not consider the metabolic flux and balance of the organism, leading to ineffective experiments. Therefore, an integrated systems approach based on fast screening, 'omics' tools, and metabolic-mathematical modeling could be useful for the design and optimization of metabolic pathways, which will result in a more efficient conversion of low-cost materials to highly desired products $[6,24,94]$. In light of these observations, the combination of metabolomics, fluxomics, and synthetic biology is a powerful tool for prospecting novel metabolic routes, as well as producing chemicals derived from biomass.

\section{Plant metabolomics}

Nowadays, the production of bioethanol relies almost entirely on sucrose and starch from crops. Major efforts have been taken to understand and manipulate the pathways involved in carbohydrate storage and partitioning (for review, see [2]). In this sense, few descriptive metabolomics studies attempted to unravel the correlation between metabolites, developmental stages, and sucrose accumulation pattern in sugarcane [95] or the impact of environmental stress in different species used for bioenergy [96,97].

One obvious sustainable way to enhance biofuel production would be by increasing yield per planted area. Interestingly, a number of important traits, such as stress resistance and postharvest processing, are largely dependent on metabolic content [8], implying a vast potential for manipulation of metabolic phenotypes via classical breeding $[26,27,29,30,98,99]$. This approach has several advantages in relation to genetic markers, as it does not rely on the genome sequence nor does it depend on understanding the complex mixture of segregating patterns among the progenies. Metabolomics has been successfully used to investigate the relationship between biomass yield and metabolic composition of plants $[26,27,29,99,100]$. In summary, the data showed that a combination of metabolites correlates with biomass rather than a single compound, suggesting the identification of metabolic signatures for complex traits [29]. These findings were extended by a more detailed 
analysis of recombinant inbred line (RIL) and near isogenic line (NILs) populations in Arabidopsis that revealed a couple of hot spots in which yield quantitative trait loci (QTL) overlapped with a large number of metabolite accumulation QTL [27]. Similarly, a comparative analysis of the root metabolome of parental maize inbred lines and their corresponding hybrids showed that the metabolic profile of each hybrid is distinct from its parents [28]. Altogether, these results indicated that metabolomicsassisted breeding should accelerate the selection process and, in combination with other high-throughput technologies, will probably shorten the time required for the production of elite lines [8].

Of the biomass produced by land plants, $70 \%$ is estimated to represent plant cell walls, considered a highly promising source for lignocellulosic ethanol $[7,101]$. Lignocellulosic biomass includes materials such as agricultural residues (e.g., sugarcane bagasse and straw, corn stover), forestry residues, and various industrial wastes. The major problems in converting structural polysaccharides into ethanol lies in cellulose's recalcitrant nature and the complex matrix embedded by it, which interferes with the access of hydrolytic enzymes mainly due to the presence of the phenolic macromolecular structure lignin [101]. To ensure the successful production of lignocellulosic ethanol, it has been suggested that the elucidation of cell wall-related pathways could provide the means for engineering its structure as well as other bioproducts. In this sense, lignin has garnered special attention due to its potential value-added products, such as plastic and vanillin, and for this reason, many efforts have been made to improve gene annotation of the pathway [102-104], molecular phenotyping [105], and metabolic and integrative analysis of plants with altered lignin content [102,106-108]. In an excellent study, comprehensive analysis of 20 Arabidopsis mutants of genes encoding for enzymes of the lignin pathway was accomplished using a systems approach [107]. The authors were able to identify over 560 compounds using GC-MS and UHPLC-MS, and by correlating this data with transcriptome in a network, they found genes with a putative role in phenolic metabolism, gaining insight into lignin regulatory network, and finally, had a systems view of plant response to perturbations in the pathway [107]. It is interesting to note that those mutants did not present a clear growth phenotype, and molecular characterization was crucial for understanding the compensation mechanisms in the lignin pathway. Such information may help in engineering plants with altered lignin content suitable for the bio-based economy.

Another renewable fuel that can be produced from plants is biodiesel. Plant oils are composed of triacylglycerols (TGAs), like fatty acyl chains, which are chemically similar to the bulk of molecules found in petrol [3]. Despite great potential for the use of plant biodiesel, there are a number of factors restricting its production, such as cold-temperature properties, competition with other industrial sectors, and limited feedstock (for review, see [3]). In this sense, different strategies have been applied to alter the fatty acid profile and identify plant species able to produce these compounds in greater scale. One example is Physaria fendleri, which synthesizes the highly valued fatty acid lesquerolic acid for application in cosmetic, plastic, and biofuel industries. Metabolomics characterization of this species using GC-MS and UHPLCMS has provided important insights into fatty acid synthesis and also points to the importance of metabolic annotation into pathways [109]. The emerging field of lipidomics has garnered much attention in the last few years due to the possibility for profiling large-scale lipid classes such as TGA, glycerolipids, among others [110,111]. This technology could also assist in the discovery of new feedstocks for biofuel production, which has been already successfully applied to microalgae in the selection of strains and/or optimization of biomass growth [112,113]. However, the use of lipidomics in higher plants has been limited to annotation of pathways [114-116] and response to environmental stresses [117], with no direct application for biofuels so far.

\section{Conclusions}

We have highlighted the current status of metabolomics and its power in bioenergy-oriented studies. Although great advances in several analytic platforms allow for the assessment of hundreds of metabolites in complex biological samples, compound identification and data analysis and integration are still bottlenecks that make this approach a challenge. Efforts to further understand metabolic changes in microorganism during the harsh ethanolic fermentation steps, as well as the prospection of novel routes and strains for biomass conversion, indicate that metabolomics plays an indispensable role in diagnostics and metabolic engineering. In addition, metabolomics links phenotype to genotype and has great potential for application in various plant science areas such as metabolomicsassisted breeding and systems biology. For this reason, metabolomics could boost plant yield and microorganism performance for biotechnological purposes in bioenergy research.

\section{Competing interests}

The authors declare that they have no competing interests.

\section{Authors' contributions}

PVA, CC and MCMM wrote the manuscript. CC prepared figures and tables. All authors read and approved the final manuscript.

\section{Acknowledgements}

The authors thank EMBRAPA and CTBE for permission to publish this work. We thank Mauricio Parra and Ryan Green for critical reading on the manuscript. This work was supported by funding from the Max Planck Society (CC), the National Council for Scientific and Technological 
Development (CNPq-Brazil, Grant 402755-2012-0 to CC) and the FAPESP (São Paulo Research Foundation, Brazil, Grant 2012/19561-0 to (C).

\section{Author details}

'Embrapa Agroenergy - Estação Biológica (PqEB), s/no, W3 Norte, Brasília, DF 70770-901, Brazil. 'Brazilian Bioethanol Science and Technology Laboratory/ CNPEM, Rua Giuseppe Máximo Scolfaro 10000, Campinas, SP 13083-970, Brazil. ${ }^{3}$ Max-Planck-partner group at the Brazilian Bioethanol Science and Technology Laboratory/CNPEM, Rua Giuseppe Máximo Scolfaro 10000, Campinas, SP 13083-970, Brazil.

\section{Received: 31 March 2014 Accepted: 7 October 2014}

\section{Published online: 30 October 2014}

\section{References}

1. Smith AM (2008) Prospects for increasing starch and sucrose yields for bioethanol production. Plant J 54(4):546-558

2. Byrt CS, Grof CPL, Furbank RT (2011) C4 Plants as biofuel feedstocks: optimising biomass production and feedstock quality from a lignocellulosic perspective. J Integr Plant Biol 53(2):120-135

3. Durrett TP, Benning C, Ohlrogge J (2008) Plant triacylglycerols as feedstocks for the production of biofuels. Plant J 54(4):593-607

4. Krizek BA (2009) Making bigger plants: key regulators of final organ size. Curr Opin Plant Biol 12(1):17-22

5. Winkelhausen E, Kuzmanova S (1998) Microbial conversion of d-xylose to xylitol. J Ferment Bioeng 86(1):1-14

6. de Jong B, Siewers V, Nielsen J (2012) Systems biology of yeast: enabling technology for development of cell factories for production of advanced biofuels. Curr Opin Biotechnol 23(4):624-630

7. Pauly M, Keegstra K (2008) Cell-wall carbohydrates and their modification as a resource for biofuels. Plant J 54(4):559-568

8. Fernie AR, Schauer N (2009) Metabolomics-assisted breeding: a viable option for crop improvement? Trends Genet 25(1):39-48

9. Keurentjes JJB (2009) Genetical metabolomics: closing in on phenotypes. Curr Opin Plant Biol 12(2):223-230

10. Baker JM, Hawkins ND, Ward JL, Lovegrove A, Napier JA, Shewry PR, Beale $\mathrm{MH}$ (2006) Ametabolomic study of substantial equivalence of field-grown genetically modified wheat. Plant Biotechnol J 4(4):381-392

11. Kusano M, Fukushima A, Kobayashi M, Hayashi N, Jonsson P, Moritz T, Ebana K, Saito K (2007) Application of a metabolomic method combining onedimensional and two-dimensional gas chromatography-time-of-flight/mass spectrometry to metabolic phenotyping of natural variants in rice. J Chromatogr B Analyt Technol Biomed Life Sci 855(1):71-79

12. Kusano M, Redestig H, Hirai T, Oikawa A, Matsuda F, Fukushima A, Arita M, Watanabe S, Yano M, Hiwasa-Tanase K, Ezura H, Saito K (2011) Covering chemical diversity of geneticallymodified tomatoes using metabolomics for objective substantial equivalence assessment. Plos One 6(2):e16989

13. Watanabe M, Kusano M, Oikawa A, Fukushima A, Noji M, Saito K (2008) Physiological roles of the beta-substituted alanine synthase gene family in Arabidopsis. Plant Physiol 146(1):310-320

14. Hirai MY, Klein M, Fujikawa Y, Yano M, Goodenowe DB, Yamazaki Y, Kanaya S, Nakamura Y, Kitayama M, Suzuki H, Sakurai N, Shibata D, Tokuhisa J, Reichelt M, Gershenzon J, Papenbrock J, Saito K (2005) Elucidation of geneto-gene and metabolite-to-gene networks in Arabidopsis by integration of metabolomics and transcriptomics. J Biol Chem 280(27):25590-25595

15. Jung JY, Kim TY, Ng CY, Oh MK (2012) Characterization of GCY1 in Saccharomyces cerevisiae by metabolic profiling. J Appl Microbiol 113(6):1468-1478

16. Park C, Yun S, Lee SY, Park K, Lee J (2012) Metabolic profiling of Klebsiella oxytoca: evaluation of methods for extraction of intracellular metabolites using UPLC/Q-TOF-MS. App Biochem Biotechnol 167(3):425-438

17. Yoshida R, Tamura T, Takaoka C, Harada K, Kobayashi A, Mukai Y, Fukusaki E (2010) Metabolomics-based systematic prediction of yeast lifespan and its application for semi-rational screening of ageing-related mutants. Aging Cell 9(4):616-625

18. Caldana C, Degenkolbe T, Cuadros-Inostroza A, Klie S, Sulpice R, Leisse A, Steinhauser D, Fernie AR, Willmitzer L, Hannah MA (2011) High-density kinetic analysis of the metabolomic and transcriptomic response of Arabidopsis to eight environmental conditions. Plant J 67(5):869-884

19. Gibon Y, Usadel B, Blaesing OE, Kamlage B, Hoehne M, Trethewey R, Stitt M (2006) Integration of metabolite with transcript and enzyme activity profiling during diurnal cycles in Arabidopsis rosettes. Genome Biol 7(8):R76
20. Guy C, Kaplan F, Kopka J, Selbig J, Hincha DK (2008) Metabolomics of temperature stress. Physiol Plant 132(2):20-235

21. Kaplan F, Kopka J, Sung DY, Zhao W, Popp M, Porat R, Guy CL (2007) Transcript and metabolite profiling during cold acclimation of Arabidopsis reveals an intricate relationship of cold-regulated gene expression with modifications in metabolite content. Plant J 50(6):967-981

22. Bergdahl B, Heer D, Sauer U, Hahn-Hägerdal B, van Niel EW (2012) Dynamic metabolomics differentiates between carbon and energy starvation in recombinant Saccharomyces cerevisiae fermenting xylose. Biotechnol Biofuels 5(1):34

23. Jozefczuk S, Klie S, Catchpole G, Szymanski J, Cuadros-Inostroza A, Steinhauser D, Selbig J, Willmitzer L (2010) Metabolomic and transcriptomic stress response of Escherichia coli. Mol Syst Biol 6(1):634

24. Toya Y, Shimizu H (2013) Flux analysis and metabolomics for systematic metabolic engineering of microorganisms. Biotechnol Adv 31(6):818-826

25. Hasunuma T, Sanda T, Yamada R, Yoshimura K, Ishii J, Kondo A (2011) Metabolic pathway engineering based on metabolomics confers acetic and formic acid tolerance to a recombinant xylose-fermenting strain of Saccharomyces cerevisiae. Microb Cell Fact 10(1):2

26. Keurentjes JJB, Fu J, de Vos CH, Lommen A, Hall RD, Bino RJ, van der Plas LH, Jansen RC, Vreugdenhil D, Koornneef M (2006) The genetics of plant metabolism. Nat Genet 38(7):842-849

27. Lisec J, Meyer RC, Steinfath M, Redestig H, Becher M, Witucka-Wall H, Fiehn O, Törjék O, Selbig J, Altmann T, Willmitzer L (2008) Identification of metabolic and biomass QTL in Arabidopsis thaliana in a parallel analysis of RIL and IL populations. Plant J 53(6):960-972

28. Lisec J, Römisch-Margl L, Nikoloski Z, Piepho HP, Giavalisco P, Selbig J, Gier A, Willmitzer $L$ (2011) Corn hybrids display lower metabolite variability and complex metabolite inheritance patterns. Plant J 68(2):326-336

29. Meyer RC, Steinfath M, Lisec J, Becher M, Witucka-Wall H, Törjék O, Fiehn O, Eckardt A, Willmitzer L, Selbig J, Altmann T (2007) The metabolic signature related to high plant growth rate in Arabidopsis thaliana. Proc Natl Acad Sci U S A 104(11):4759-4764

30. Sulpice R, Pyl ET, Ishihara H, Trenkamp S, Steinfath M, Witucka-Wall H, Gibon Y, Usadel B, Poree F, Piques MC, Von Korff M, Steinhauser MC, Keurentjes JJ, Guenther M, Hoehne M, Selbig J, Fernie AR, Altmann T, Stitt M (2009) Starch as a major integrator in the regulation of plant growth. Proc Natl Acad Sci U S A 106(25):10348-10353

31. Herrgard MJ, Swainston N, Dobson P, Dunn WB, Arga KY, Arvas M, Blüthgen $N$, Borger $S$, Costenoble R, Heinemann $M$, Hucka $M$, Le Novère $N$, Li P, Liebermeister W, Mo ML, Oliveira AP, Petranovic D, Pettifer S, Simeonidis E, Smallbone K, Spasić I, Weichart D, Brent R, Broomhead DS, Westerhoff HV, Kirdar B, Penttilä M, Klipp E, Palsson BØ, Sauer U, Oliver SG, et al. (2008) A consensus yeast metabolic network reconstruction obtained from a community approach to systems biology. Nat Biotechnol 26(10):1155-1160

32. Nielsen J, Pronk JT (2012) Metabolic engineering, synthetic biology and systems biology. Fems Yeast Res 12(2):103

33. Zhang J, Carey V, Gentleman R (2003) An extensible application for assembling annotation for genomic data. Bioinformatics 19:155-156

34. Hasunuma T, Kondo A (2012) Development of yeast cell factories for consolidated bioprocessing of lignocellulose to bioethanol through cell surface engineering. Biotechnol Adv 30(6):1207-1218

35. Hall RD (2006) Plant metabolomics: from holistic hope, to hype, to hot topic. New Phytol 169(3):453-468

36. Lei ZT, Huhman DV, Sumner LW (2011) Mass spectrometry strategies in metabolomics. J Biol Chem 286(29):25435-25442

37. Lisec J, Schauer N, Kopka J, Willmitzer L, Fernie AR (2006) Gas chromatography mass spectrometry-based metabolite profiling in plants. Nat Protoc 1(1):387-396

38. Fukushima A, Kusano M (2013) Recent progress in the development of metabolome databases for plant systems biology. Front Plant Sci 4:73

39. Faijes M, Mars A, Smid E (2007) Comparison of quenching and extraction methodologies for metabolome analysis of Lactobacillus plantarum. Microb Cell Fact 6(1):27

40. Hall RD (2011) Plant metabolomics in a nutshell: potential and future challenges. In: Ann Plant Rev, vol 43. Wiley-Blackwell, Oxford, pp 1-24

41. Fiehn $\mathrm{O}$ (2002) Metabolomics - the link between genotypes and phenotypes. Plant Mol Biol 48(1-2):155-171

42. Villas-Bôas SG, Højer-Pedersen J, Akesson M, Smedsgaard J, Nielsen J (2005) Global metabolite analysis of yeast: evaluation of sample preparation methods. Yeast 22(14):1155-1169 
43. Canelas AB, ten Pierick A, Ras C, Seifar RM, van Dam JC, van Gulik WM, Heijnen JJ (2009) Quantitative evaluation of intracellular metabolite extraction techniques for yeast metabolomics. Anal Chem 81(17):7379-7389

44. Sasidharan K, Soga T, Tomita M, Murray DB (2012) A yeast metabolite extraction protocol optimised for time-series analyses. Plos One 7(8):e44283

45. Neubauer S, Haberhauer-Troyer C, Klavins K, Russmayer H, Steiger MG, Gasser B, Sauer M, Mattanovich D, Hann S, Koellensperger G (2012) U13C cell extract of Pichia pastoris - a powerful tool for evaluation of sample preparation in metabolomics. J Sep Sci 35(22):3091-3105

46. Kim S, Lee do Y, Wohlgemuth G, Park HS, Fiehn O, Kim KH (2013) Evaluation and optimization of metabolome sample preparation methods for Saccharomyces cerevisiae. Anal Chem 85(4):2169-2176

47. Lindon JC, Nicholson JK (2008) Analytical technologies for metabonomics and metabolomics, and multi-omic information recovery. TrAC Trends Anal Chem 27(3):194-204

48. Nicholson JK, Buckingham MJ, Sadler PJ (1983) High resolution 1 H n.m.r. studies of vertebrate blood and plasma. Biochem J 211(3):605-615

49. Bedair M, Sumner LW (2008) Current and emerging mass-spectrometry technologies for metabolomics. TrAC Trends Anal Chem 27(3):238-250

50. Okazaki Y, Saito K (2012) Recent advances of metabolomics in plant biotechnology. Plant Biotechnol Rep 6(1):1-15

51. Dass C (2007) Basics of Mass Spectrometry. Fundamentals of contemporary mass spectrometry. John Wiley \& Sons, Inc, Hoboken, In, pp 1-14

52. Koek MM, Muilwijk B, van der Werf MJ, Hankemeier T (2006) Microbial metabolomics with gas chromatography/mass spectrometry. Anal Chem 78(4):1272-1281

53. Mashego M, Rumbold K, De Mey M, Vandamme E, Soetaert W, Heijnen JJ (2007) Microbial metabolomics: past, present and future methodologies. Biotechnol Lett 29(1):1-16

54. Garcia DE, Baidoo EE, Benke PI, Pingitore F, Tang YJ, Villa S, Keasling JD (2008) Separation and mass spectrometry in microbial metabolomics. Curr Opin Microbiol 11(3):233-239

55. Vielhauer O, Zakhartsev M, Horn T, Takors R, Reuss M (2011) Simplified absolute metabolite quantification by gas chromatography-isotope dilution mass spectrometry on the basis of commercially available source material. J Chromatogr B Analyt Technol Biomed Life Sci 879(32):3859-3870

56. Li Y, Shrestha B, Vertes A (2007) Atmospheric pressure infrared MALDI imaging mass spectrometry for plant metabolomics. Anal Chem 80(2):407-420

57. Sun T, Wetzel SJ, Johnson ME, Surlow BA, Patton-Vogt J (2012) Development and validation of a hydrophilic interaction liquid chromatography-tandem mass spectrometry method for the quantification of lipid-related extracellular metabolites in Saccharomyces cerevisiae. J Chromatogr B 897:1-9

58. Hsu C-C, ElNaggar MS, Peng Y, Fang J, Sanchez LM, Mascuch SJ, Møller KA, Alazzeh EK, Pikula J, Quinn RA, Zeng Y, Wolfe BE, Dutton RJ, Gerwick L, Zhang L, Liu X, Månsson M, Dorrestein PC (2013) Real-time metabolomics on living microorganisms using ambient electrospray ionization flow-probe. Anal Chemi 85(15):7014-7018

59. Villas-Bôas SG, Mas S, Akesson M, Smedsgaard J, Nielsen J (2005) Mass spectrometry in metabolome analysis. Mass Spectrom Rev 24(5):613-646

60. Saito K, Dixon RA, Willmitzer L (2006) Plant metabolomics. In: Biotechnology in Agriculture and Forestry, vol. 57. Springer, Berlin Heidelberg

61. Junot C, Fenaille F, Colsch B, Bécher F (2013) High resolution mass spectrometry based techniques at the crossroads of metabolic pathways. Mass Spectrom Rev 33(6):471-500

62. Pope GA, MacKenzie DA, Defernez M, Roberts IN (2009) Metabolic footprinting for the study of microbial biodiversity. Cold Spring Harb Protoc 2009(5):pdb.prot5222

63. Ejsing CS, Sampaio JL, Surendranath V, Duchoslav E, Ekroos K, Klemm RW, Simons K, Shevchenko A (2009) Global analysis of the yeast lipidome by quantitative shotgun mass spectrometry. Proc Natl Acad Sci U S A 106 (7):2136-2141

64. Devaiah SP, Roth MR, Baughman E, Li M, Tamura P, Jeannotte R, Welti R, Wang X (2006) Quantitative profiling of polar glycerolipid species from organs of wild-type Arabidopsis and a phospholipase Dalpha1 knockout mutant. Phytochemistry 67(17):1907-1924

65. Cao M, Koulman A, Johnson LJ, Lane GA, Rasmussen S (2008) Advanced data-mining strategies for the analysis of direct-infusion ion trap mass spectrometry data from the association of perennial ryegrass with its endophytic fungus, Neotyphodium Iolii. Plant Physiol 146(4):1501-1514
66. Giavalisco P, Li Y, Matthes A, Eckhardt A, Hubberten HM, Hesse H, Segu S, Hummel J, Köhl K, Willmitzer L (2011) Elemental formula annotation of polar and lipophilic metabolites using (13) C, (15) N and (34) S isotope labelling, in combination with high-resolution mass spectrometry. Plant J 68(2):364-376

67. Nakabayashi R, Kusano M, Kobayashi M, Tohge T, Yonekura-Sakakibara K, Kogure N, Yamazaki M, Kitajima M, Saito K, Takayama H (2009) Metabolomics-oriented isolation and structure elucidation of 37 compounds including two anthocyanins from Arabidopsis thaliana. Phytochemistry 70(8):1017-1029

68. De Vos RCH, Moco S, Lommen A, Keurentjes JJ, Bino RJ, Hall RD (2007) Untargeted largescale plant metabolomics using liquid chromatography coupled to mass spectrometry. Nat Protoc 2(4):778-791

69. Kopka J, Walther D, Allwood JW, Goodacre R (2011) Progress in chemometrics and biostatistics for plant applications, or: a good red wine is a bad white wine. In: Annual Plant Reviews, vol 43. Wiley-Blackwell, Oxford, pp 317-342

70. Shulaev V (2006) Metabolomics technology and bioinformatics. Brief Bioinform 7(2):128-139

71. Redestig H, Kobayashi M, Saito K, Kusano M (2011) Exploring matrix effects and quantification performance in metabolomics experiments using artificial biological gradients. Anal Chem 83(14):5645-5651

72. Boccard J, Rudaz S (2014) Harnessing the complexity of metabolomic data with chemometrics. J Chemom 28(1):1-9

73. Xia J, Wishart DS (2011) Metabolomic data processing, analysis, and interpretation using MetaboAnalyst. Curr Protoc Bioinformatics 34:Chapter 14

74. Fiehn O, Kind T, Barupal DK (2011) Data processing, metabolomic databases and pathway analysis. In: Annual Plant Reviews, vol 43. Wiley-Blackwell, Oxford, pp 367-406

75. Redestig H, Szymanski J, Hirai MY, Selbig J, Willmitzer L, Nikoloski Z, Saito K (2011) Data integration, metabolic networks and systems biology. In: Annual Plant Reviews, vol 43. Wiley-Blackwell, Oxford, pp 261-316

76. Cuadros-Inostroza A, Caldana C, Redestig H, Kusano M, Lisec J, Peña-Cortés H, Willmitzer L, Hannah MA (2009) TargetSearch - a Bioconductor package for the efficient preprocessing of GCMS metabolite profiling data. BMC Bioinformatics 10:12

77. Luedemann A, von Malotky L, Erban A, Kopka J (2012) TagFinder: preprocessing software for the fingerprinting and the profiling of gas chromatography-mass spectrometry based metabolome analyses. Methods Mol Biol 860:255-286

78. Lommen A (2009) MetAlign: interface-driven, versatile metabolomics tool for hyphenated fullscan mass spectrometry data preprocessing. Anal Chem 81(8):3079-3086

79. Smith CA, Want EJ, O'Maille G, Abagyan R, Siuzdak G (2006) XCMS: processing mass spectrometry data for metabolite profiling using nonlinear peak alignment, matching, and identification. Anal Chem 78(3):779-787

80. Krastanov A (2010) Metabolomics - the state of art. Biotechnol Biotech Eq 24(1):1537-1543

81. Sugimoto M, Kawakami M, Robert M, Soga T, Tomita M (2012) Bioinformatics tools for mass spectroscopy-based metabolomic data processing and analysis. Curr Bioinform 7(1):96-108

82. Peralta-Yahya PP, Keasling JD (2010) Advanced biofuel production in microbes. Biotechnol J 5(2):147-162

83. Ding MZ, Li BZ, Cheng JS, Yuan YJ (2010) Metabolome analysis of differential responses of diploid and haploid yeast to ethanol stress. OMICS 14(5):553-561

84. Sassner P, Galbe M, Zacchi G (2008) Techno-economic evaluation of bioethanol production from three different lignocellulosic materials. Biomass Bioenerg 32(5):422-430

85. Rudolf A, Karhumaa K, Hahn-Hägerdal B (2009) Ethanol production from traditional and emerging raw materials. In: Satyanarayana T, Kunze G (ed) Yeast Biotechnology: Diversity and Applications. Springer Science, Netherlands, pp 489-513

86. Almeida JRM, Runquist D, Sànchez i Nogué V, Lidén G, Gorwa-Grauslund MF (2011) Stressrelated challenges in pentose fermentation to ethanol by the yeast Saccharomyces cerevisiae. Biotechnol J 6(3):286-299

87. Wohlbach DJ, Kuo A, Sato TK, Potts KM, Salamov AA, Labutti KM, Sun H, Clum A, Pangilinan JL, Lindquist EA, Lucas S, Lapidus A, Jin M, Gunawan C, Balan V, Dale BE, Jeffries TW, Zinkel R, Barry KW, Grigoriev IV, Gasch AP (2011) Comparative genomics of xylose-fermenting fungi for enhanced biofuel production. Proc Natl Acad Sci U S A 108(32):13212-13217 
88. Hahn-Hägerdal B, Karhumaa K, Jeppsson M, Gorwa-Grauslund MF (2007) Metabolic engineering for pentose utilization in Saccharomyces cerevisiae. Adv Biochem Eng Biotechnol 108:147-177

89. Karhumaa K, Påhlman AK, Hahn-Hägerdal B, Levander F, Gorwa-Grauslund MF (2009) Proteome analysis of the xylose-fermenting mutant yeast strain TMB 3400. Yeast 26(7):371-382

90. Parachin NS, Bergdahl B, van Niel EW, Gorwa-Grauslund MF (2011) Kinetic modelling reveals current limitations in the production of ethanol from xylose by recombinant Saccharomyces cerevisiae. Metab Eng 13(5):508-517

91. Runquist D, Hahn-Hagerdal B, Radstrom P (2010) Comparison of heterologous xylose transporters in recombinant Saccharomyces cerevisiae. Biotechnol Biofuels 3(1):5

92. Runquist D, Hahn-Hägerdal B, Bettiga M (2010) Increased ethanol productivity in xyloseutilizing Saccharomyces cerevisiae via a randomly mutagenized xylose reductase. Appl Environ Microbiol 76(23):7796-7802

93. Nielsen J, Jewett MC (2008) Impact of systems biology on metabolic engineering of Saccharomyces cerevisiae. FEMS Yeast Res 8(1):122-131

94. Ellis DI, Goodacre R (2012) Metabolomics-assisted synthetic biology. Curr Opin Biotechnol 23(1):22-28

95. Glassop D, Roessner U, Bacic A, Bonnett GD (2007) Changes in the sugarcane metabolome with stem development. Are they related to sucrose accumulation? Plant Cell Physiol 48(4):573-584

96. Sicher RC, Barnaby JY (2012) Impact of carbon dioxide enrichment on the responses of maize leaf transcripts and metabolites to water stress. Physiol Plant 144(3):238-253

97. Ings J, Mur LA, Robson PR, Bosch M (2013) Physiological and growth responses to water deficit in the bioenergy crop Miscanthus $x$ giganteus. Front Plant Sci 4:468

98. Kliebenstein DJ (2009) Advancing genetic theory and application by metabolic quantitative trait loci analysis. Plant Cell 21(6):1637-1646

99. Lisec J, Steinfath M, Meyer RC, Selbig J, Melchinger AE, Willmitzer L, Altmann T (2009) Identification of heterotic metabolite QTL in Arabidopsis thaliana RIL and IL populations. Plant J 59(5):777-788

100. Meyer RC, Kusterer B, Lisec J, Steinfath M, Becher M, Scharr H, Melchinger AE, Selbig J, Schurr U, Willmitzer L, Altmann T (2010) QTL analysis of early stage heterosis for biomass in Arabidopsis. Theor Appl Genet 120(2):227-237

101. Li X, Weng J-K, Chapple C (2008) Improvement of biomass through lignin modification. Plant J 54(4):569-581

102. Bottcher A, Cesarino I, Santos AB, Vicentini R, Mayer JL, Vanholme R, Morree K, Goeminne G, Moura JC, Nobile PM, Carmello-Guerreiro SM, Anjos IA, Creste S, Boerjan W, Landell MG, Mazzafera P (2013) Lignification in sugarcane: biochemical characterization, gene discovery, and expression analysis in two genotypes contrasting for lignin content. Plant Physiol 163(4):1539-1557

103. Shen H, Mazarei M, Hisano H, Escamilla-Trevino L, Fu C, Pu Y, Rudis MR, Tang Y, Xiao X, Jackson L, Li G, Hernandez T, Chen F, Ragauskas AJ, Stewart CN, Jr, Wang ZY, Dixon RA (2013) A genomics approach to deciphering lignin biosynthesis in switchgrass. Plant Cell 25(11):4342-4361

104. Shi R, Sun YH, Li Q, Heber S, Sederoff R, Chiang VL (2010) Towards a systems approach for lignin biosynthesis in Populus trichocarpa: transcript abundance and specificity of the monolignol biosynthetic genes. Plant Cell Physiol 51(1):144-163

105. Raes J, Rohde A, Christensen JH, Van de Peer Y, Boerjan W (2003) Genomewide characterization of the lignification toolbox in Arabidopsis. Plant Physiol 133(3):1051-1071

106. Rohde A, Morreel K, Ralph J, Goeminne G, Hostyn V, De Rycke R, Kushnir S, Van Doorsselaere J, Joseleau JP, Vuylsteke M, Van Driessche G, Van Beeumen J, Messens E, Boerjan W (2004) Molecular phenotyping of the pal1 and pal2 mutants of Arabidopsis thaliana reveals far-reaching consequences on phenylpropanoid, amino acid, and carbohydrate metabolism. Plant Cell 16(10):2749-2771

107. Vanholme R, Storme V, Vanholme B, Sundin L, Christensen JH, Goeminne G, Halpin C, Rohde A, Morreel K, Boerjan W (2012) A systems biology view of responses to lignin biosynthesis perturbations in Arabidopsis. Plant Cell 24(9):3506-3529

108. Tschaplinski T, Standaert RF, Engle NL, Martin MZ, Sangha AK, Parks JM, Smith JC, Samuel R, Jiang N, Pu Y, Ragauskas AJ, Hamilton CY, Fu C, Wang ZY, Davison BH, Dixon RA, Mielenz JR (2012) Down-regulation of the caffeic acid O-methyltransferase gene in switchgrass reveals a novel monolignol analog. Biotechnol Biofuels 5(1):71
109. Cocuron J-C, Anderson B, Boyd A, Alonso AP (2014) Targeted metabolomics of Physaria fendleri, an industrial crop producing hydroxy fatty acids. Plant Cell Physiol 55(3):620-633

110. Blanksby SJ, Mitchell TW (2010) Advances in mass spectrometry for lipidomics. Annu Rev Anal Chem 3(1):433-465

111. Shevchenko A, Simons K (2010) Lipidomics: coming to grips with lipid diversity. Nat Rev Mol Cell Biol 11(8):593-598

112. MacDougall K, McNichol J, McGinn PJ, O'Leary SJ, Melanson JE (2011) Triacylglycerol profiling of microalgae strains for biofuel feedstock by liquid chromatography-high-resolution mass spectrometry. Anal Bioanal Chem 401(8):2609-2616

113. Chen D, Yan X, Xu J, Su X, Li L (2013) Lipidomic profiling and discovery of lipid biomarkers in Stephanodiscus sp. under cold stress. Metabolomics 9 (5):949-959

114. Horn PJ, Chapman KD (2014) Lipidomics in situ: insights into plant lipid metabolism from high resolution spatial maps of metabolites. Prog Lipid Res 54:32-52

115. Simanshu DK, Zhai X, Munch D, Hofius D, Markham JE, Bielawski J, Bielawska A, Malinina L, Molotkovsky JG, Mundy JW, Patel DJ, Brown RE (2014) Arabidopsis accelerated cell death 11, ACD11, is a ceramide-1-phosphate transfer protein and intermediary regulator of phytoceramide levels. Cell Rep 6(2):388-399

116. Haslam RP, Ruiz-Lopez N, Eastmond P, Moloney M, Sayanova O, Napier JA (2013) The modification of plant oil composition via metabolic engineeringbetter nutrition by design. Plant Biotechnol J 11(2):157-168

117. Zheng G, Tian B, Zhang F, Tao F, Li W (2011) Plant adaptation to frequent alterations between high and low temperatures: remodelling of membrane lipids and maintenance of unsaturation levels. Plant Cell Environ 34(9):1431-1442

\section{doi:10.1186/s40538-014-0022-0}

Cite this article as: Abdelnur et al:: Metabolomics applied in bioenergy.

Chemical and Biological Technologies in Agriculture 2014 1:22.

\section{Submit your manuscript to a SpringerOpen ${ }^{\odot}$ journal and benefit from:}

- Convenient online submission

Rigorous peer review

- Immediate publication on acceptance

- Open access: articles freely available online

- High visibility within the field

- Retaining the copyright to your article

Submit your next manuscript at $>$ springeropen.com 